\title{
Beira Rio FM 104.9: A Frequência da educação na comunidade Quilombola de Bom Jardim da Prata
}

\author{
Beira Rio FM 104.9: A Frequency of education in the Quilombola community of Bom \\ Jardim da Prata
}

\begin{abstract}
Autores
Kasandra Isabella Helouise Mingoti Poague. Engenheira Ambiental Universidade Federal de Minas Gerais (UFMG) e Mestranda no programa de Pós-Graduação em Saneamento, Meio Ambiente e Recursos Hídricos da UFMG (SMARH) E-mail: poaguek@gmail.com
\end{abstract}

Recebido em: 16/01/2019 Aprovado em: 10/09/2019

DOl: $10.12957 /$ interag.2019. 39478

\section{Relato de experiência}

O presente trabalho apresenta o potencial da hipermídia radiofônica como ferramenta de educação ambiental a partir de um estudo de caso aplicado em comunidades quilombolas circundantes ao município de São Francisco (MG). Por três dias, foram veiculados pela rádio comunitária Beira Rio FM 104.9 localizada em uma das comunidades, programas ao vivo articulados em quadros de forma a conciliar a discussão de questões ambientais mais proeminentes nestas com temas cotidianos, a fim de que de se tornassem mais interessantes e lúdicos aos ouvintes. O engajamento da população das comunidades com os quadros do programa evidencia a grande competência que a mídia rádio possui no alcance e capacidade de forma-

\section{Abstract}

This paper presents the potential of radiophonic hypermedia as a tool for environmental education based on a case study applied to quilombola communities surrounding the city of São Francisco (MG). For three days, community radio broadcast Beira Rio FM 104.9, located in one of the communities, presented live programs articulated in cadres in order to reconcile the discussion of environmental issues more prominent in these localities with daily themes, in order to make them more interesting and playful to listeners. The engagement of the local population with the program's cadres demonstrates the great competence that the radio media possesses in reaching and training the people, in the case of quilombola communities, by 
ção das pessoas, em se tratando de comunidades quilombolas, seja levando estas a agirem de acordo com os pressupostos de ecologia e cidadania, como também no seu autorreconhecimento como um grupo étnico-social.

Palavras- chave: Educação Ambiental, Rádio, Quilombolas

\section{Área Temática: Educação \\ Linha Temática: Educação Rural}

causing them to act according to the assumptions of ecology and citizenship and also in their self-recognition as an ethnic-social group.

Keywords: Environmental Education, Radio, Quilombolas

\section{Introdução}

Não obstante a expressiva representatividade numérica das comunidades quilombolas e da população tradicional negra no Brasil (cerca de 0,3\% da população total brasileira'), as famílias quilombolas são expostas a grave situação de vulnerabilidade social. No que tange ao acesso a serviços e à infraestrutura de saneamento básico, diversos estudos apontam para um histórico de convivência em condições precárias ao acesso a água potável, coleta e destinação adequada de resíduos sólidos e esgotamento sanitário, conforme exposto por dados das famílias quilombolas inseridas no Cadastro Único para Programas Sociais do Governo Federal (Cadúnico) 2,3 (Tabela 1).

\begin{tabular}{|c|c|c|c|}
\hline \multicolumn{4}{|c|}{ Situação do Domicílio Quilombola } \\
\hline & $\mathrm{jul} / 12$ & $\mathrm{jan} / 13$ & set/14 \\
\hline Abastecimento & $\begin{array}{l}\text { 62\% não possui água } \\
\text { canalizada }\end{array}$ & $\begin{array}{l}55,21 \% \text { não possui água } \\
\text { canalizada }\end{array}$ & $\begin{array}{c}34,6 \% \text { é abastecida pela } \\
\text { rede geral de } \\
\text { distribuição }\end{array}$ \\
\hline $\begin{array}{c}\text { Posse de } \\
\text { banheiro/sanitário }\end{array}$ & $\begin{array}{c}36 \% \text { não possui banheiro ou } \\
\text { sanitário }\end{array}$ & $\begin{array}{c}\text { 33,06\% não possui } \\
\text { banheiro ou sanitário. }\end{array}$ & - \\
\hline Saneamento & $\begin{array}{l}76 \% \text { não possui saneamento } \\
\text { adequado ( } 28 \% \text { possui esgoto } \\
\text { a céu aberto e } 48 \% \text { fossa } \\
\text { rudimentar) }\end{array}$ & $\begin{array}{c}54,07 \% \text { não possui } \\
\text { saneamento adequado } \\
(15,07 \% \text { possui esgoto a } \\
\text { céu aberto e } 39 \% \\
\text { fossa rudimentar) }\end{array}$ & $\begin{array}{c}68,9 \% \text { não possui } \\
\text { saneamento adequado } \\
(9,9 \% \text { possui esgoto a } \\
\text { céu aberto e } 59 \% \\
\text { fossa rudimentar) }\end{array}$ \\
\hline $\begin{array}{l}\text { Destinação de } \\
\text { resíduos }\end{array}$ & $\begin{array}{c}58 \% \text { queima ou enterra o lixo } \\
\text { no território; e apenas } 20 \% \\
\text { possui coleta adequada }\end{array}$ & $\begin{array}{l}57,98 \% \text { queima ou enterra } \\
\text { o lixo no território; e } \\
\text { apenas } 21,19 \% \text { possui } \\
\text { coleta adequada }\end{array}$ & $\begin{array}{c}26,9 \% \text { possui coleta de } \\
\text { lixo }\end{array}$ \\
\hline
\end{tabular}

Fonte: BRASIL, 2013; BRASIL, 2014a.

Tabela 1 - Situação do Domicílio Quilombola de 2012 a 2014. 
Em se tratando de comunidades quilombolas, assegurar o direito ao saneamento, e como consequência indireta, à saúde, é um marco da luta para o estabelecimento de padrões de equidade étnico-racial, visto que existe uma dívida histórica com a população negra no âmbito do saneamento desde a época colonial com os famosos escravos "tigres", e a saúde da população negra ainda persiste sob um quadro de desigualdades ao longo da história ${ }^{4}$.

Segundo a Organização Mundial de Saúde (OMS), saneamento é o controle de todos os fatores do meio físico do homem, que exercem ou podem exercer efeitos nocivos sobre o bem- estar físico, mental e social. Comumente, a partir desta definição, entende-se de maneira equivocada, que as ações de saneamento consistem apenas na intervenção dos fatores do meio físico, interpretado como infraestrutura do ambiente. Olaerts ${ }^{5}$ ressalva que, restringir as ações de saneamento básico somente como medidas de infraestrutura, desconsidera a estreita relação entre saneamento e saúde pública e exclui os determinantes socioambientais (fatores ambientais, econômicos, culturais, étnico/raciais, psicológicos e comportamentais) que influenciam na ocorrência de problemas de saúde pública.

O próprio Plano Nacional de Saneamento Básico ${ }^{6}$ reconhece que apenas medidas estruturais, ou seja, os tradicionais investimentos em obras e intervenções físicas com intuito de suprir o déficit de cobertura pelos serviços de saneamento básico, não são, por si só, suficientes para garantir e perpetuar um adequado acesso da população a estes serviços.

Referindo-se a comunidades quilombolas, a cultura e as tradições próprias desempenham um relevante papel na sustentabilidade dos serviços de saneamento e saúde pública. Apesar da ausência de condições sanitárias adequadas na comunidade de Caiana dos Crioulos (Paraná), não foram descritas doenças e sintomas como verminoses e diarreias, justificado pelo alto índice de acesso aos meios de comunicação como rádio, televisão e outros veículos aliado ao uso da medicina tradicional ${ }^{7}$. Amorim ${ }^{8}$ destaca que no remanescente de quilombos Boqueirão (Bahia), ao contrário do que se esperava devido aos baixos níveis de escolaridade da população, precárias condições das residências, qualidade insatisfatória das instalações sanitárias e baixas condições socioeconômicas da população ativa, não foi encontrada uma alta prevalência de parasitoses intestinais, situação essa atribuída ao uso popular de plantas medicinais para tratamento de doenças e manutenção da saúde.

Estes resultados indicam que os programas de melhoria de infraestrutura de saneamento em comunidades rurais só se mostrarão efetivos com um adequado trabalho de educação sanitária em conjunto, garantindo o correto acesso às informações sobre uso adequado dos sistemas sanitários, medidas preventivas e curativas, e disseminação de práticas de higiene, sendo preservadas e valorizadas as características culturais da população, posto que: "educação ambiental e meio ambiente não podem ser vistos de maneira isolada das relações sociais que transpassam suas ações"

A implantação de rádios comunitárias em comunidades quilombolas é uma das ações do Programa Brasil Quilombola e da Agenda Social Quilombola no eixo de promoção de direitos e cidadania, o qual é definido como:

"fomento de iniciativas de garantia de direitos promovidas por diferentes órgãos públicos e organizações da sociedade civil, estimulando a participação ativa dos representantes quilombolas nos espaços coletivos de controle e participação social, como os conselhos e fóruns locais e nacionais de políticas públicas, de modo a promover o acesso das comunidades ao conjunto das ações definidas pelo governo e seu envolvimento no monitoramento daquelas que são implementadas em cada município onde houver comunidades remanescentes de quilombos." 
A comunicação comunitária se constituiu como espaço de democratização da comunicação, exercício da cidadania e fortalecimento de identidades culturais ${ }^{10}$. Nesse contexto, as rádios comunitárias se destacam por serem um meio de comunicação capaz de garantir o direito à voz, incontestável a todos os segmentos sociais, e por perpetuar a importância da comunicação para preservação da memória e identidade cultural das comunidades negras.

O presente trabalho consiste na execução de um programa Radiofônico de Educação Ambiental nas comunidades quilombolas ao redor do município de São Francisco, Minas Gerais, executado sob a abrangência do projeto de extensão denominado "Monitoramento participativo de sistemas simplificados de abastecimento de água em uma comunidade quilombola de Minas Gerais" desenvolvido no âmbito do Edital ProEXT 2016 (Programa de Apoio a Extensão Universitária MEC/SESu).

O programa pretendia abarcar três objetivos: promover a aproximação dos executores do projeto com os moradores das comunidades do entorno, os quais seriam pelas próximas duas semanas entrevistadas sobre as condições sanitárias de suas residências; transmitir aos moradores procedimentos básicos de melhoria de condições de saneamento como fervura e filtragem da água; e promover o autor-' reconhecimento dos moradores como um grupo étnico-social, profundamente vinculado ao seu território e à resistência à opressão histórica escravista, dotada de direitos econômicos, sociais e culturais.

\section{Metodologia}

Característico aos municípios da região norte do estado de Minas Gerais, a cidade de São Francisco é circundada por núcleos populacionais rurais formados por remanescentes de Quilombos, entre eles o território quilombola de Bom Jardim da Prata (Figura 1), que abrange em uma área de 63.168,15 hectares, 630 famílias divididas em 15 localidades ${ }^{11}$. Reconhecido pela Fundação Cultural Palmares como área remanescente de quilombo, e há 10 anos em processo de titulação de suas terras, o território localiza-se na margem esquerda do rio São Francisco ${ }^{12}$.

O acesso à região é restrito, uma vez que a cidade sede situa-se na margem direita do rio São Francisco, sendo necessária uma travessia por balsa seguida de um trajeto por uma estrada de terra para acessar o núcleo populacional rural formado por remanescentes de Quilombos ${ }^{13}$.

Equipes multidisciplinares compostas por alunos dos cursos de graduação de Engenhara Civil, Engenharia Ambiental e Ciências Socioambientais da Universidade Federal de Minas Gerais ficaram hospedadas em casas em distintas localidades do território quilombola durante quatro dias, período em que realizaram um levantamento de informações sobre as condições de saneamento local por meio da aplicação de um questionário individual com os moradores. Estudos precedentes ao projeto indicavam que nas localidades prevaleciam condições inadequadas de abastecimento e tratamento de água para consumo humano, esgotamento sanitário e destinação de resíduos sólidos. ${ }^{12,14}$

Durante a etapa de diagnóstico e avaliação de condições de saneamento das localidades, por três dias entre as 08 e 09 horas de manhã, o programa ao vivo foi veiculado pela Rádio Comunitária Beira Rio FM 104.9, localizada na localidade de Bom Jardim da Prata. A região de alcance do sinal da rádio abrangia as localidades de Bom Jardim da Prata, Peãozeiro, Benedito Costa, Lagedo e a cidade de São Francisco. 


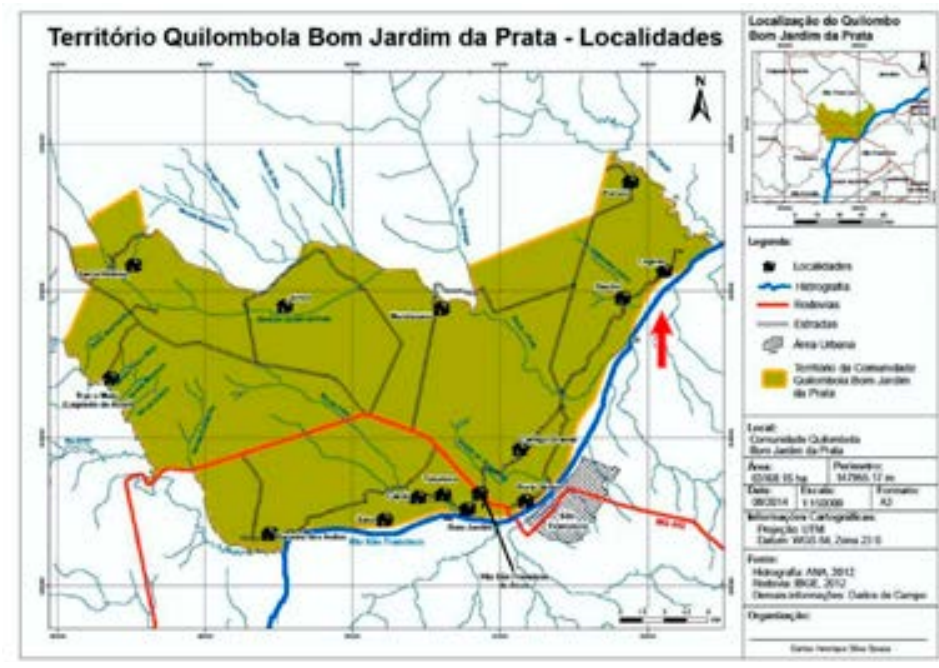

Figura 1 - Mapa do Território Quilombola de Bom Jardim da Prata e suas 15 localidades, resultante do Laudo Antropológico realizado em cooperação técnica entre a Universidade Estadual de Montes Claros (UNIMONTES) e o Incra/MG. A seta à direita mostra as localidades de Lagedo e Riacho.

A programação radiofônica foi articulada em quadros de forma a conciliar a discussão das questões ambientais mais precárias nas comunidades com temas cotidianos, a fim de que o programa se tornasse mais interessante e lúdico aos ouvintes. Os referidos quadros são apresentados pela Tabela 2.

\begin{tabular}{|c|c|}
\hline QUADRO & DESCRIÇÃO \\
\hline RADIONOVELA & $\begin{array}{c}\text { Curtas histórias de } 5 \text { minutos de duração em que Detetive Alberto } \\
\text { Libota resolvia um mistério em São Francisco com seus } \\
\text { conhecimentos sobre saneamento e meio ambiente }\end{array}$ \\
\hline BATE BOLA-QUILOMBOLA & $\begin{array}{c}\text { Diálogo entre os protagonistas da radionovela sobre o que significa } \\
\text { ser quilombola, seus direitos e dificuldades vivenciados por } \\
\text { moradores de comunidades quilombolas }\end{array}$ \\
\hline $\begin{array}{l}\text { DICAS DE COMO DEIXAR } \\
\text { SUA ÁGUA GOSTOSINHA }\end{array}$ & $\begin{array}{c}\text { Sugestões de soluções de tratamento de água a nível local com } \\
\text { apropriação do conhecimento popular da comunidade; Exemplo: } \\
\text { uso de sementes da árvore encontrada na região, Moringa Oleifera, } \\
\text { como coagulante natural de água }\end{array}$ \\
\hline SORTEIO MAROTO & $\begin{array}{l}\text { Sorteio de uma muda de Moringa à primeira pessoa que ligasse } \\
\text { respondendo corretamente uma pergunta sobre as dicas de como } \\
\text { deixar sua água mais adequada ao consumo humano }\end{array}$ \\
\hline BONDE DA MORINGA & $\begin{array}{c}\text { Paródia da música de sucesso "Cerol na Mão" da banda Bonde do } \\
\text { Tigrão, com o passo a passo de como utilizar a Moringa e seus } \\
\text { benefícios }\end{array}$ \\
\hline
\end{tabular}

Tabela 2 - Quadros do programa radiofônico e sua breve descrição. 
Além de músicas intercalando os quadros, as quais os moradores poderiam pedir com dedicatórias, era feita a divulgação e convite das festas das comunidades a fim de promover sua união e fortalecimento.

De forma análoga, por vezes, os alunos faziam uma breve divulgação do projeto, apresentando seus objetivos e informando a possível visita aos moradores, assim como agradecendo o apoio e atenção.

Devido à grande aderência da população da localidade de Bom Jardim da Prata ao sorteio da muda de Moringa Oleifera, os alunos distribuíram pacotes contendo 10 sementes secas da planta (Figura 2), a todos os moradores da comunidade que responderam o questionário de avaliação das condições de saneamento, incluindo os que participaram do sorteio e que não foram contemplados. Para cada pessoa que recebeu um pacote era explicado como plantar, cultivar e o modo de utilização da semente na água.

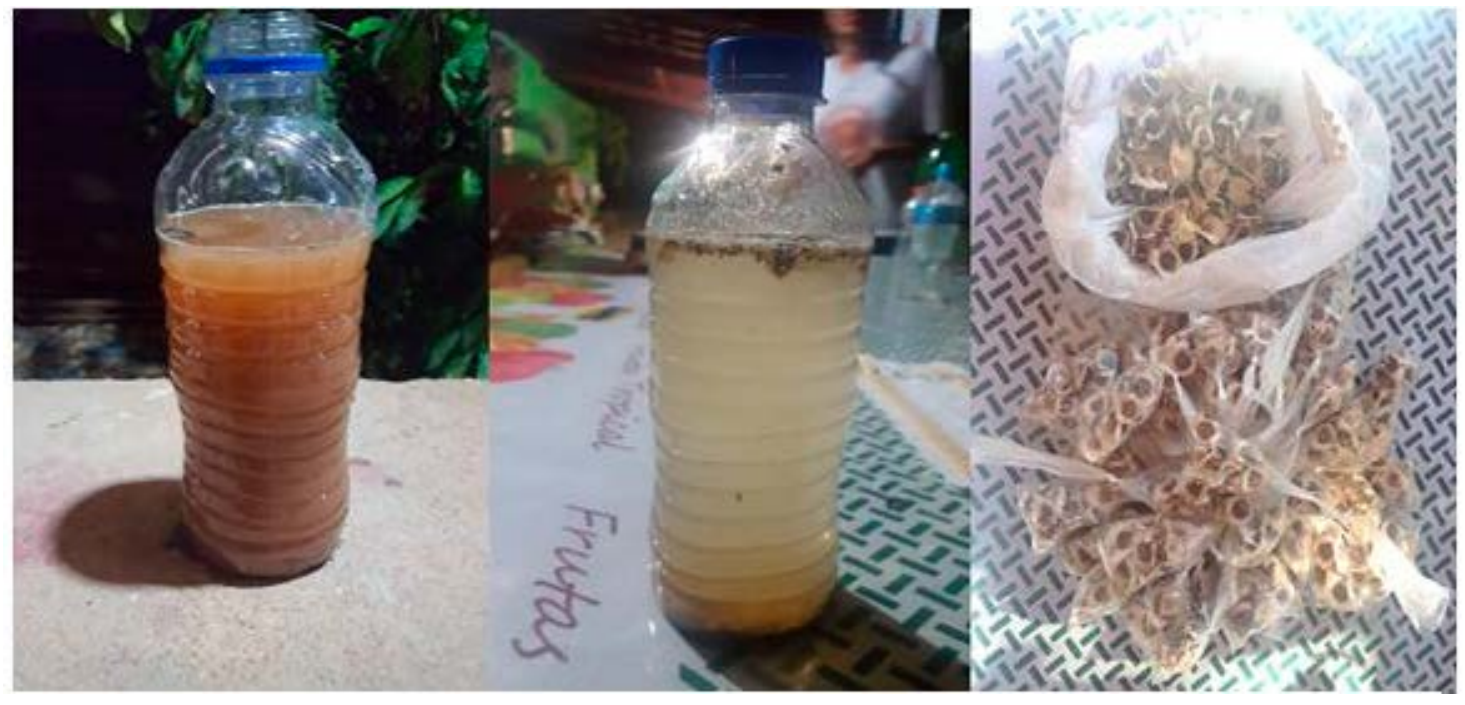

Figura 2 - Água antes e após aplicação de sementes de Moringa Oleifera e pacotes com as sementes entregues aos moradores.

\section{Resultados e discussão}

O sucesso e a repercussão do programa foram constatados em diversas instâncias: por meio de pedidos de músicas dedicadas, assim como ligações para participação do sorteio; comentários dos ouvintes durante as visitas para realização dos questionários de saneamento; divulgação do programa de rádio e do projeto na Rádio Nacional de Brasília durante o programa Clayton Aguiar; indagação dos moradores sobre quando seria a continuidade do programa; constatação do plantio da muda de Moringa Oleifera, durante uma visita feita à casa do ganhador do sorteio, uma semana após a finalização do programa; expectativa dos moradores que receberam os pacotes de sementes quanto ao crescimento da árvore. Os programas foram disponibilizados em uma página do site Youtube ${ }^{15}$.

A utilização de radionovelas como ferramenta de educação ambiental também foi recentemente adotada pelo Instituto Mamirauá. A radionovela "A cor da Água", exibida dentro do programa de rádio "Ligado no Mamirauá" veiculado pela Rádio Educação Rural, cujo público- alvo são comunidades ribeirinhas da Amazônia, informa dicas sobre tratamento de 
água16. De acordo com relatos dos pesquisadores realizadores do programa, o formato de radionovelas já tinha sido experimentado em atividades de sensibilização e se mostrou muito eficiente no diálogo com comunitários das Reservas Mamirauá e Amanã, no Amazonas ${ }^{16}$.

A adoção de rádios comunitárias como mídia de comunicação é frequente em comunidades de remanescentes de quilombos ${ }^{17,18,10,19}$. Presume-se que esse tipo de meio de comunicação, denominado de alternativo, popular, comunitário, participativa, contra-hegemônica e horizontal, proporciona um espaço de protagonismo social e da voz a minorias sociais silenciadas e de menor visibilidade. ${ }^{18,10}$

O serviço de radiodifusão comunitária, além de objetivar "fornecer oportunidade à difusão de ideias, elementos de cultura, tradições e hábitos sociais da comunidade"20 proporciona a transparência e acesso a informações, princípio geral que deve ser respeitado para garantia do direito à água e ao esgotamento sanitário (DAEHS), assim como o direito de participar livremente da vida cultural da comunidade. ${ }^{21,22}$

A despeito da sua curta duração, o programa de rádio revelou-se como essencial para aceitação da população e aderência da realização do diagnóstico de condições de saneamento das comunidades. Em se tratando de comunidades rurais, onde nem todos possuem acesso às mídias - como internet e televisão - e considerando que comunidades quilombolas em sua grande maioria foram excluídas da educação forma'2 , a execução do programa em uma rádio comunitária possibilitou uma educação verdadeiramente universal e democrática, com programas elaborados respeitando a cultura e hábitos locais. Fortuna ${ }^{24}$ ressalta que a rádio configura-se como o mais eficiente meio de comunicação entre populações que vivem em áreas de difícil acesso, como no presente caso, se tornando um importante aliado para a preservação e conservação do meio ambiente através de educação e informação ambiental. Ademais, o rádio é um meio de comunicação que não priva o interlocutor de exercer atividades simultâneas, independe de energia elétrica, visto que o aparelho pode ser utilizado com baterias e pilhas, de custo reduzido, fácil acomodação, e, por trabalhar apenas com a questão sonora, estimula a imaginação dos ouvintes. 10, 24

Almeida, Neuls e Guindani10 realçam que, em contrapartida, as vantagens em se utilizar as rádios comunitárias como meio de comunicação, a vida limitada desses instrumentos é resultado de diversos obstáculos como a obtenção de outorga junto ao Ministério das Telecomunicações, a manutenção do funcionamento das emissoras pela falta de recursos financeiros, limitações técnicas, falta de capacitação dos comunicadores e pela excessiva fiscalização dos órgãos governamentais.

\section{Conclusões}

Foram perceptíveis pequenas mudanças do comportamento cotidiano dos moradores que passaram a agir de acordo com os pressupostos de ecologia e cidadania aconselhados durantes os programas. Isso demonstra o grande potencial que a mídia rádio possui no alcance e capacidade de formação das pessoas dessas comunidades e a necessidade da continuação de programas do mesmo cunho para evitar que os conhecimentos transmitidos sejam esquecidos.

\section{Referências}

1. BRASIL. Secretaria Especial de Políticas de Promoção da Igualdade Racial. Quilombos e Quilombolas: indicadores e propostas de monitoramento de políticas. Brasília, DF, 
2018. Disponível em:< http://www.mdh.gov.br/biblioteca/consultorias/quilombos-e-quilombolas-indicadores-e-propostas-de-monitoramento-de-politicas $>$. Acesso em 14 de outubro de 2018.

2. BRASIL. Secretaria Especial de Políticas de Promoção da Igualdade Racial. Programa Brasil Quilombola - Guia de Políticas Públicas Para Comunidades Quilombolas. Brasília, DF, 2013. Disponível em:<http://www.seppir.gov.br/portal-antigo/arquivos-pdf/guia-pbq>. Acesso em 22 de dez. 2016.

3. BRASIL. Secretaria Especial de Políticas de Promoção da Igualdade Racial. Programa Brasil Quilombola - Painéis de Monitoramento PQP. Brasília, DF, 2014a. Disponível em: < http://monitoramento.seppir.gov.br/>. Acesso em: 22 dez. 2016.

4. VIEIRA, A. B. D.; MONTEIRO, P. S. Comunidade quilombola: análise do problema persistente do acesso à saúde, sob o enfoque da Bioética de Intervenção. Saúde em Debate, Rio de Janeiro, v. 37, n. 99, p. 610-618, 2013.

5. OLAERTS, L. Programa de Saneamento Básico em Assentamento Precário: Estudo de Caso Quilombo Cantão das Lombas. 2013. 100 f. Trabalho de Conclusão de Curso (Gradruação em Engenharia Ambiental) - Universidade Federal do Rio Grande do Sul, Porto Alegre, 2013.

6. BRASIL. Ministério das Cidades. Secretaria Nacional de Saneamento Ambiental. Plano Nacional de Saneamento Básico - PLANSAB. Brasília, DF, 2014b. Disponível em: $<$ http://www.cidades.gov.br/images/stories/ArquivosSNSA/PlanSaB/plansab_texto_editado_para_download.pdf $>$. Acesso em 22 de dez. 2016.

7. SILVA, J. A. N. Condições sanitárias e de saúde em Caiana dos Crioulos, uma comunidade quilombola do estado da Paraíba. Saúde e Sociedade, v.16, n.2, p.111-124, 2007.

8. AMORIM, M. M; TOMAZI, L; SILVA, R. A. A; GESTINARI, R. S; FIGUEIREDO, T. B. Avaliação das condições habitacionais e de saúde da Comunidade Quilombola Boqueirão, Bahia, Brasil. Bioscience Journal, v. 29, n. 4, p. 1049-1057, 2013.

9. JONHASEN, C. C.; PINTO, J. M. R.; TEIXEIRA, R.; SUDAN, D. C.; RIBEIRO, L. Educação Ambiental nas Ondas da Rádio UPS de Ribeirão Preto. Fórum Ambiental da Alta Paulista, v.07, n.06, p.1012-1018, 2011.

10. ALMEIDA, C. D.; NEULS, G. S.; GUINDANI, J. F.; Rádio Comunitária Quilombo FM: comunidades comunitárias, sujeitos da sua história, cidadãos da sua cidade. In: Conferência Brasileira de Mídia Cidadã, 5, Guarapuava. Anais... Guarapuava, 2009. p. 835 -851

11. COSTA, J. B. DE A.; DAYRELL, C. A.; CAA-NM; OLIVEIRA, C. L. DE. Relatório Antropológico de caracterização histórica, econômica, ambiental e sócio-cultural do Quilombo Bom Jardim da Prata - São Francisco (MG). Montes Claros, 2015.

12. VILELA, D. R. Metodologia participativa na instalação de sistemas de abastecimento e tratamento de água em áreas rurais: 0 caso da comunidade quilombola de Lagedo. 2016. 288 f. Tese (Doutorado) - Pós-graduação em Saneamento, Meio Ambiente e Recursos Hídricos, Departamento de Engenharia Ambiental e Sanitária, Universidade Federal de Minas Gerais, Belo Horizonte, 2016.

13. POAGUE, K. I. H. M.; PÁDUA, V. L. Desafios na luta pela promoção da equidade e universalização do saneamento básico em comunidades quilombolas. In: Martins, C. H. G.; Figueiredo, G. L. A.; Akerman, M (Eds). Vulnerabilidade e saúde: grupos em cena por visibilidade no espaço urbano.São Paulo: Editora HUCITEC, 523 pp.

14. SILVA, A. S. R. Autogestão de Sistemas Rurais de Abastecimento de Água: estudo de caso na comunidade quilombola de Lagedo. São Francisco - MG. 2016. 161 f. Disser- 
tação (Mestrado) - Pós-graduação em Saneamento, Meio Ambiente e Recursos Hídricos, Departamento de Engenharia Ambiental e Sanitária - Universidade Federal de Minas Gerais, Belo Horizonte, 2016.

15. SÃO FRANCISCO PROEXT UFMG 2016 - Youtube. 2016. Disponível em: <https:// www.youtube.com/channel/UCDizhhKMEf4-X287xhUC57w>. Acesso em: 24 de setembro de 2016

16. MAMIRAUÁ. Para divulgar cuidados com a água, Instituto Mamirauá cria radionovela. 2018. Disponível em: < https://www.mamiraua.org.br/pt-br/comunicacao/ noticias/2018/3/20/para-divulgar-cuidados-com-a-agua-instituto-mamiraua-cria-radionovela/?fbclid=IwAR1QJwD8n8eSSfcfRUadMTOXitLc87OE2voypYYOyawAKII5fE3la5B4sIU>. Acesso em 18 de novembro de 2018.

17. SCALCON, V.; GOLDSCHMIDT, I.; TORRESCASANA, M. Expressões da democratização dos meios de comunicação e da sociedade na experiência da Rádio Comunitária de Quilombo. In: Congresso de Ciências da Comunicação na Região Sul, 13, Chapecó. Anais... Chapecó, 2012.

18. TESSAROTO, M. A. O. Entre Estabelecidos e Outsiders: A construção da Informação Social nas Rádios Comunitárias pelas Comunidade Rurais e Quilombolas. In: Congresso de Ciências da Comunicação da Região Nordestes, 18, Caruaru. Anais...Caruaru, 2016

19. DIAS, L. O. Além de uma simples onda: Recepção, Cidadania e rádio-poste no QuiIombo Barra da Aroeira. In: Congresso Brasileiro de Ciências da Comunicação, 32, Curitiba. Anais... Curitiba, 2009

20. BRASIL. Lei no $\mathbf{9 , 6 1 2}$ de 19 de Fevereiro de 1998. Institui o Serviço de Radiodifusão Comunitária e dá outras providências. Diário Oficial [da] República Federativa do Brasil, Brasília, DF.

21. ONU - Organização das Nações Unidas. Assembleia Geral. Resolution A/ RES/64/292. The human right to water and sanitation. 2010. Disponível em: <http:// www.un.org/en/ga/search/view_doc.asp?symbol=A/RES/64/292.> Acesso em 22 de outubro de 2018.

22. ONU - Organização das Nações Unidas. Assembleia Geral. Universal Declaration of Human Rights. 1948. Disponível em: <http://www.un.org/en/universal-declaration-human-rights/>. Acesso em 22 de outubro de 2018.

23. ARRUTI, J. M. Quilombos. In: PINHO, Osmundo (Org). Raça: Perspectivas Antropológicas. 2 ed. Salvador: ABA/Ed. da Unicamp/EDUFBA, 2008. p. 315- 350.

24. FORTUNA, D. B. Educomunicação: Importância da Apropriação dos Media (rádio) no Exercício da Educação Ambiental e Cidadania da Comunidade. 2007. Disponível em: $<$ http://www.bocc.ubi.pt/pag/fortuna-danielle-educomunicacao-importancia-da-apropriacao-dos-media.pdf>. Acesso em 20 de dezembro de 2018. 